\title{
Relationships of DVT (Deep Vein Thrombosis) Based on Ultrasound with 72 Hours ICU Patients Using Mechanical Ventilation at RSUP. Haji Adam Malik Medan
}

\author{
Okky Hudaya $^{1 *}$, Yutu Solihat ${ }^{2}$, Bastian Lubis ${ }^{2}$, Akhyar H. Nasution ${ }^{3}$ \\ 1. Resident of Anesthesiology and Intesive Care USU Medical Faculty, RSUP H. Adam Malik Medan \\ 2. Staff of Anesthesiology and Intensive Care Department of RSUP H. Adam Malik Medan \\ 3. Head of Anesthesiology and Intensive Care Department of RSUP H. Adam Malik Medan \\ *Email : okkyhudaya@gmail.com
}

DOI: 10.29322/IJSRP.10.02.2020.p9831

http://dx.doi.org/10.29322/IJSRP.10.02.2020.p9831

\begin{abstract}
INTRODUCTION: Deep vein thrombosis is formation of thrombus which often attacks deep veins, especially lower extremities. VTE itself has an incidence rate 1 per 1000 people and mortality rate around 60,000-100,000 per year. ${ }^{1,2}$ Patients with critical illness also have risk factors, in context of ICU care. Some studies write incidence of patients experiencing DVT in general ICU care around $8 \%$ to $40 \%{ }^{3}$ Therefore, this study aims to determine relationship between 72 hours ICU patient using mechanical ventilation and incidence of DVT. METHOD: This study is a prospective cohort analytic study to see relationship between 72 hours ICU treatment using mechanical ventilation with incidence of DVT in ICU patients at H. Adam Malik General Hospital Medan during August-September 2019. Inclusion criteria were patients aged 18-65 years and patients who using mechanical ventilation after 72 hours treatment at ICU. RESULT: Study was followed by 39 samples treated at ICU Haji Adam Malik Hospital Medan. It was found that proportion of male sample was 22 people (56.4\%), most age group was 48-62 years as many as 15 people (38.5\%), all samples did not experience DVT on first day care, found 10 sample (25.6\%) who had DVT on the 72-hour treatment ( $\mathrm{p}<0.001)$. Then results of analysis between a two variables have a significant relationship, ( $\mathrm{p}$ value $<0.05$; CI: $95 \%$ ). DISCUSSION: In this study, number of men tends to be more than women. There are no definitive theories regarding sex population associated with ICU care. The results of study of the 72-hour DVT incidence were also further strengthened by the results of analysis relationship between two variables of the DVT incidence and the ICU treatment for 72 hours. CONCLUSION: There is an association between 72 hours ICU care using mechanical ventilation with incidence of DVT in this study. (p value: $0,001$, pvalue $<0,005)$.
\end{abstract}

Keyword: Deep Vein Thrombosis, Intensive Care Unit, Mechanical Ventilation

\section{INTRODUCTION}

Deep vein thrombosis or DVT is a formation of a thrombus or blood clot which generally attacks deep veins especially lower extremities (such as veins in the calf, femoral and popliteal) or deep veins in the pelvic region. Generally, this diagnosis is combined in VTE (venous thromboembolism). VTE itself has an incidence rate 1 per 1000 people and a mortality rate around 60,000-100,000 per year. ${ }^{1,2}$ Patients with critical illness also have risk factors, in the context of ICU care. Variable risk factors make this condition very complex. The development increased by presence of age factors, orthopedic operative measures, trauma, cancer to immobility factors. Pregnancy, hormonal therapy, obesity and several other hypercoagulable conditions are risk factors for DVT

Patients with critical illness also have risk factors, in context of ICU care. Some studies write incidence of patients experiencing DVT in general ICU care around 8\% to 40\%. Observative research conducted by Miri Mohammad et al in Iran in 1387 ICU care patients showed that ICU length of stay was an independent factor for the occurrence of DVT $(p<0.01) .{ }^{3.4}$ Prophylaxis was needed for DVT cases in ICU care. The most widely used therapy is anticoagulant. LMWH, and unfractionated heparin also vitamin K antagonists have been used as therapeutic option. ${ }^{4}$ Maria Bodi dan Adriano Peris, 2016, ${ }^{40}$ conducted an observational 
study to find prevalence and incidence of DVT in ICU patients with a 72-hour incidence rate of around 11\% and decreased when given thromboprophylaxis to $4 \%$. Study, which involved postoperative patients and treated in post-operative ICU, showed DVT resolution within 72 hours, and only a small proportion ascended to more proximal veins.

Based on the background, aim of this study was to determine the relationship between 72 hour ICU patient care using mechanical ventilation and incidence of DVT.

\section{METHODS}

The study was conducted after passing ethical clearance from the ethical research committee Faculty of Medicine, University of North Sumatra / RSUP HAM. This study is a prospective cohort analytic study to see relationship between 72 hours ICU care using mechanical ventilation and incidence of DVT. The study was conducted at RSUP H. Adam Malik Medan in August September 2019. The inculsion criteria were patients aged 18-65 years and patients who used mechanical ventilation after 72 hours treatment at ICU. Exclusion criteria were families of patients who were not willing to be sampled, patients who had a history of DVT, patients who had a history of using anti-coagulant drugs, and patients who underwent surgery on lower limbs. With drop-out criteria, are patient declared dead, and observed patient withdraws from the study / withdrawal of informed consent. Enrolled research samples using consecutive sampling method. The study was conducted after explaining to patient's family about purpose, manner and benefits of this examination and subsequently in the patient's family who will be the sample first signed an informed consent. Basic data was recorded by researchers in the ICU room at H. Adam Malik General Hospital Medan such as name, gender, place / date of birth, address, telephone number and occupation.

\section{RESULTS}

This study was followed by 39 samples of patients treated at ICU Haji Adam Malik Hospital Medan. The distribution of sample characteristics explained including, gender, age, DVT images on treatment days 1, 2 and 3 in ICU. Furthermore, the results of the analysis of two variables are occurence of DVT with length of stay in the ICU. It was found that proportion of samples that male were 22 people $(56.4 \%)$ and female 17 people (43.6\%). It was found that age group most commonly found in 48-62 years old by 15 people $(38.5 \%)$ and the smallest age group was $>62$ years by 7 people $(7.9 \%)$ (Table 1$)$.

Table 1. Characteristic of sample

\begin{tabular}{|c|c|c|c|}
\hline & \multicolumn{3}{|c|}{ Characteristic } \\
\hline & $\mathrm{N}$ & Percentage (\%) & $P$ value \\
\hline \multicolumn{3}{|l|}{ Sex } & \multirow{3}{*}{$0,032^{+}$} \\
\hline Male & 22 & 56,4 & \\
\hline Female & 17 & 43,6 & \\
\hline \multicolumn{3}{|l|}{ Age (years) } & \multirow{5}{*}{$0,046^{+}$} \\
\hline $18-32$ & 8 & 20,5 & \\
\hline $33-47$ & 9 & 23,1 & \\
\hline $48-72$ & 15 & 38,5 & \\
\hline$>62$ & 7 & 17,9 & \\
\hline \multicolumn{3}{|l|}{ DVT Events } & \multirow{4}{*}{$0,001 *$} \\
\hline Day 1 & 0 & 0 & \\
\hline Day 2 & 0 & 0 & \\
\hline Day 3 & 10 & 25,6 & \\
\hline
\end{tabular}

${ }^{+}$Kolmogorov-Smirnov, *Friedman test

In this study there were no DVT positive patients on the first day, in other words the entire sample of 39 people did not experience DVT on the first day of care. Of 39 samples examined on the second day no samples were found with DVT. In other words, negative results were also found in all samples of 39 people (100\%). From this study found positive DVT patients based on the results of Doppler ultrasound examination. From table, it can be found that positive patients have DVT in 72 hours in ICU 
in 10 people $(25.6 \%)$ and negative results in DVT are 29 people $(74.4 \%)$. Non-parametric data in this study were analyzed using the Friedmann test. In above analysis the asymp sig value ( $\mathrm{p}$ value) is 0.001 . Then the results of the analysis are two variables have a significant relationship, ( $\mathrm{p}$ value $<0.05$; $\mathrm{CI}$ : $95 \%$ ).

\section{DISCUSSION}

In this study, number of men tends to be more than women. Basically there are no definitive theories about association between gender and ICU care. Research conducted by Larson Emma, et al. ${ }^{6}$ in Scandinavian assumes that patient with critical illness who must be treated in intensive care units based on the severity of disease, depends on comorbidity and not on age, socio-economic or gender. However, in contrast research conducted by Valentine et al, in Austria show that men are greater count in ICU care compared to women, as measured by disease severity level, in addition it also supported by studies conducted in Sweden that $60 \%$ of ICUs are filled by male patients. It was seen that women have more progressive reaction both to the administration of aspirin and others, thereby reducing the need for ICU care.

Based on age, this research found that most common age was 48-62 years old. This age group was found as many as 15 people $(38.5 \%)$ of total sample. This study is also consistent with study conducted by Garland et al. ${ }^{7}$ that age is a dependent factor on ICU care. In this study, average age of the population was $64.5 \pm 16.4$ years. This research shows same results in this study. Age is an unmodified factor that greatly affects patient's health and cure rates for an illness. Theoretically, age will increase morbidity and severity of a disease, because some organs with important functions decrease it function.

On DVT examination, negative results were found on the first and second days. On the third day DVT was found in 10 of 39 samples studied. The same study was also carried out by Boddi Marie et al. ${ }^{5}$ where in the first 48 hours of patient care in ICU there is no DVT was found. Positive results and incidence of DVT was found on third day or 72 hours after ICU treatment. Based on gender, DVT in this study found $60 \%$ in men, more found in men compared to women. This study was also similarly found in studies conducted by Roach et al. ${ }^{8}$ Men have a greater risk for experiencing DVT than women.

The results of the study that 72-hour DVT incidence were also further strengthened by analysis results of relationship between two variables, which is DVT incidence and 72 hours ICU care. Some studies wrote incidence or prevalence of DVT events cannot be calculated just by using scoring. Examination of risk factors for DVT must also taken into account, not only in thrombophilic profile of each patient who entering ICU, with different medical, surgical and patient measures. Even in several studies, although some tombophylaxis was given, a significant incidence of DVT was still found. This condition is also caused by each thrombophylaxis having a various threshold that is very difficult to detect compared to several doses of anticoagulants.

\section{CONCLUSION}

There was an association between 72 hours ICU patients who used mechanical ventilation with incidence of DVT in this study. (p value: 0,001 , pvalue $<0,005)$.

\section{REFERENCES}

1. Kesieme Emeka, Kesieme Chineye, Jebbin Nje, et al. Deep vein thrombosis: a clinical review. Journal of Blood Medicine. 2011;(2): 56-59p

2. Stone Jonathan, Hangge Patrick, Albawi Hassan, et al. Deep vein thrombosis: pathogenesis, diagnosis, and medical management. Cardiovaskular Diagnosis and Therapy. 2007; 7(3): 276-284p

4. Malato Alessandra, Dentali Francesco, Siragusa Sergio, et al. The impact of deep vein thrombosis in critically ill patients: a meta-analysis of major clinical outcomes. Blood Transfus 2015; 13: 559-568p

5. Miri Muhammad, Goharani Reza, Sistanizad Mohammad. Deep Vein Thrombosis among Intensive Care Unit Patients; an Epidemiologic Study. Emergency Open Research. 2017; 5 (1):13p

6. Boddi Maria, Peris Andriano. Deep Vein Thrombosis in Intensive Care. Springer. 2016: p 1-15

7. Larsson et al. Scandinavian Journal of Trauma, Resuscitation and Emergency Medicine. 2015: (23); 108-115

8. Garland et al. Epidemiology of critically ill patients in intensive care units: a population-based observational study. Critical Care. 2013: 17(212); 1-7p

9. Roach REJ et al. Differential risks in men and women for first and recurrent venous thrombosis: the role of genes and environment. Journal of Thrombosis and Haemostasis. 2014: 12; 1593-1600p 


\section{AUTHORS}

First Author -- Okky Hudaya, Post graduate of Anaesthesiology and Intensive Therapy, Faculty of Medicine, Universitas Sumatera Utara, Medan, Indonesia, okkyhudaya@ gmail.com

Second Author--Akhyar Hamonangan Nasution, Anaesthesiology and Intensive Therapy, Faculty of Medicine, Universitas Sumatera Utara, Medan, Indonesia, ahn14112019@gmail.com

Third Author -- Asmin Lubis, Anaesthesiology and Intensive Therapy, Faculty of Medicine, Universitas Sumatera Utara,Medan, Indonesia

Correspondence Author -- Okky Hudaya, okkyhudaya@gmail.com, +62 811-6040-937 